\title{
Emotions outside the box-the new phenomenology of feeling and corporeality
}

\author{
Hermann Schmitz • Rudolf Owen Müllan • \\ Jan Slaby
}

Published online: 8 February 2011

(C) The Author(s) 2011. This article is published with open access at Springerlink.com

\begin{abstract}
The following text is the first ever translation into English of a writing by German phenomenologist Hermann Schmitz (*1928). In it, Schmitz outlines and defends a non-mentalistic view of emotions as phenomena in interpersonal space in conjunction with a theory of the felt body's constitutive involvement in human experience. In the first part of the text, Schmitz gives an overview covering some central pieces of his theory as developed, for the most part, in his massive System of Philosophy, published in German in a series of volumes between 1964 and 1980. Schmitz's System is centred on the claim that the contemporary view of the human subject is the result of a consequential historical process: A reductionist and 'introjectionist' objectification of lived experience culminating in the 'invention' of the mind (or 'soul') as a private, inner realm of subjective experience and in a corresponding 'grinding down' of the world of lived experienced to a meagre, value-neutral 'objective reality'. To counter this intellectualist trend, Schmitz puts to use his approach to phenomenology with the aim of regaining a sensibility for the nuanced realities of lived experiencehoping to make up for what was lost during the development of Western intellectual culture. Since both this text and the overall style of Schmitz's philosophising are in several ways unusual for a contemporary readership, a brief introduction is provided by philosophers Jan Slaby and Rudolf Owen Müllan, the
\end{abstract}

German title: "Entseelung der Gefühle", originally published in German in Schmitz 2010.

\section{H. Schmitz}

Emeritus Professor of Philosophy, Steinstr. 27, 24118 Kiel, Germany

R. O. Müllan

Institute of Cognitive Science, University of Osnabrück, Albrechtstr. 28, 49076 Osnabrück, Germany e-mail: rmuellan@uni-osnabrueck.de

J. Slaby $(\bowtie)$

Cluster of Excellence "Languages of Emotion", Free University Berlin, Habelschwerdter Allee 45, 14195 Berlin, Germany e-mail: slaby@zedat.fu-berlin.de 
latter of whom translated Schmitz's text into English. The introduction emphasises aspects of Schmitz's philosophy that are likely to be of relevance to contemporary scholars of phenomenological philosophy and to its potential applications in science and society.

Keywords Emotion $\cdot$ Felt body $\cdot$ Atmosphere $\cdot$ Subjectivity $\cdot$ Embodiment

\section{Introduction (by Jan Slaby \& Rudolf Owen Müllan)}

Schmitz was born in Leipzig in 1928 and soon moved to Bonn, where he later enrolled at the local University. Interestingly, he was taking the same graduate courses in philosophy as fellow eminent German postwar philosophers Jürgen Habermas and Karl-Otto Apel-a curious coincidence in light of the radically different styles and directions they were to take in their subsequent careers. Their joint academic teacher at that time was philosophical anthropologist Erich Rothacker, who in 1955 awarded Schmitz a PhD degree for a thesis on Hegel. Schmitz moved to Kiel in 1958 as an assistant professor and completed a German habilitation on the thought of the later Goethe. He was promoted to full professor at Kiel University in 1971, staying on that post throughout his career until he retired in 1993. Since then, Schmitz has been productive as ever, publishing monographs and collections of essays in rapid succession.

The ten-volume, 5,163-page strong System of Philosophy, published between 1964 and 1980, headlines Schmitz' massive oeuvre. The central concept in the System and in all of Schmitz' philosophy is that of the felt body-Leib in German. The System offers a systematic phenomenology of the felt body and the various forms of embodied experience and subsequently draws out several implications of this broad approach, resulting in phenomenological theories of subjectivity and personhood, of emotions and feelings, of space and time, of art, of religious and spiritual experience, of morals and law-to name just the key themes. The more systematic and descriptive strands in the System are embedded in rich and detailed historical expositions and critiques and moreover by abundant borrowings from literature, most notably Goethe and ancient Greek poets such as Homer and Aeschylus. Moreover, Schmitz' draws on expert literature in fields such as medicine, psychiatry, physiology, art history or architecture. The reception of Schmitz' thought is facilitated by a quite accessible, lively prose and by the absence of excessive technical jargon. Schmitz' "new phenomenology"-his somewhat grandiose label for his own approach-is thoroughly practical and application-oriented.

Although Schmitz has been inspirational to a good number of German philosophers, it would be wrong to say that he achieved a broad popularity or recognition within academic philosophy at large. ${ }^{1}$ However, he did gather a group of

\footnotetext{
${ }^{1}$ Among current German philosophy professors that draw significantly on Schmitz' work are Gernot Böhme (Darmstadt), philosopher-psychiatrist Thomas Fuchs (Heidelberg), Christoph Demmerling (Marburg), Schmitz-disciple Michael Großheim (Rostock) and Hilge Landweer (Berlin).
} 
close followers, organised, since 1992, as the Society for New Phenomenology (GNP). The society holds annual conferences and issues periodical publications. ${ }^{2}$ Interestingly, both the GNP and Schmitz' thought in general have since attracted a lot of non-philosophers - scholars from other academic disciplines such as sociology, cultural theory, the arts and performance studies as well as professionals from practical domains such as architecture, psychiatry, medicine, or urban planning. Schmitz' theory of the felt body, his notion of corporeal communication, his view of emotions as spatial atmospheres and of the various levels of personal emancipation and regression prove accessible to many and seem practically relevant in various areas. The most elaborate applications of Schmitz' thinking are to be found in psychiatry: the felt body and the various forms of corporeal sensation and corporeal dynamics such as the vital drive (explained below) seem readily deployable as guides for diagnosis and recipes for therapeutic intervention at the level of bodily practice, forming a notable alternative to overly intellectualistic and mentalistic approaches in psychiatry and psychotherapy (see Schmitz 1989; Moldzio 2004; Fuchs 2008).

In a recent interview (unpublished), Schmitz was asked why he tends so eagerly to oppose the main strands of the history of philosophical thought. This is what he answered: "That impression is incorrect. I have no quarrels with the history of philosophy - up until around 400 B.C." This remark, put forward with no outward sign of humour or irony, reveals some of the self-understanding and philosophical habitus of Hermann Schmitz. After the time of the Pre-Socratics, starting with Plato, he thinks, Western thought went astray. That is why the phenomenologist today faces the task of having to work his way through thick layers of problematic thought, theories and conceptual frameworks in order to regain an undistorted access to the phenomena of lived human experience. This is Schmitz' understanding of phenomenological philosophy. The leading question is: which of the states of affairs that present themselves in experience do I have to accept as facts? What is it to which, when I am fully receptive to what is manifest in my own experience, I cannot in earnest deny the status of being a fact? This equals Schmitz' definition of a phenomenon: A phenomenon for someone at a time is a state of affairs of which the person in question cannot in earnest deny that it is a fact. Importantly, what counts as a phenomenon is relativized to a specific person at a certain time - there is no claim to universality of phenomenological description, although Schmitz does reckon with significant agreement in the experience of various people across different times and places. In addition, phenomena in Schmitz' sense are relative to conceptual perspectives - phenomena are not literally "the things themselves" but rather things as they appear from a particular (historical, cultural, local, etc.) conceptual

\footnotetext{
${ }^{2}$ The following is taken from the English-language mission statement on the GNP's website: "The GNP [...] promotes a style of description and discussion that takes one's own observations and everyday experiences seriously. Because the impression of irrelevance, an impression that is imposed upon us in the face of contemporary philosophy, stems not from the fields of research that are generally a part of our everyday lives, but stems instead from the laboratories of the natural scientists, a world of specialists only accessible to a privileged few. Those 'real' objects closest to us have, in a peculiar manner, become alien to philosophy, as if it were embarrassing and mundane to talk about visible objects instead of elementary particles, or about the discernable felt body instead of the activities of nerve cells." (www.gnp-online.de accessed on Sept. 20, 2010).
} 
framework. In turn, the task of the phenomenologist is to access phenomena in the richness of the perspectives in which they are at any time embedded - a task that may include the critique of illegitimate, distorting representations, ideas, theories and concepts. In this context, Schmitz introduces the notion of an 'abstraction base' [Abstraktionsbasis] of a culture or epoch: a set of fundamental ideas or concepts so deeply entrenched in common experience that they provide a deep framework of intelligibility in which all things appear in experience and that shape the terms in which everything is routinely understood and interpreted. Connecting back to the historical claim stated above, Schmitz thinks that the attempt to conceptually split the personal subject into a material body and an immaterial soul marked the founding idea of an abstraction base that 2400 years later still profoundly distorts our experience of ourselves and the world. The conceptual outlook in which we find ourselves is dominated by the mind/body dualism in its various guises and with its consequent conceptions of both the person (as split up into the two fundamentally distinct spheres of body and mind) and the world (as split up into the domains of res extensa and res cogitans). What gets lost from view, on these dominant perspectives, is the felt body with its quite specific dynamics, rhythms of stirrings and corporeal movements, and its ways of being constantly involved in the manifold forms of holistic sensing of situations - rich modes of experience that cannot adequately be narrowed down to perception by means of the sense organs. Instead, sensing by means of the felt body is a holistic exchange of corporeal dynamics, a vibrant attunement to meaningful surroundings. Correspondingly, the world shows up not as a neutral realm of already separate entities but as the atmospheric fields of significant situations, opportunities or quasi-corporeal forces or 'opponents' that in the first instance become manifest to the conscious person in form of the 'internally diffuse meaningfulness' of holistic corporeal impressions. Articulation of significant situations into constellations of separate objects and structures is a later-coming achievement (although it is usually taken as primary by theoretical thinking). On this view, much of what the dominant systems of Western thought have jammed into a narrowly circumscribed inner realm of each individual's mind is set free to populate the shared sensible space around us: significant situations, affective atmospheres, meaningfulness, concrete possibilities.

As this short overview makes evident, the felt body is easily the central concept and the organising principle of Schmitz's philosophy. In relation to it, most of his key ideas, concepts and arguments come into focus. First of all, it is important not to reify the felt body and dualistically oppose it to the 'material body' [Körper in German], although Schmitz' use of the noun "Leib" might sometimes create this misleading impression. Much rather, the felt body is a feeling body-its mode of existence cannot be separated from its becoming manifest to the conscious subject in specific kinds of corporeal feeling. These corporeal feelings are crucially distinct from what usually gets described under the term 'bodily sensations' (in psychology or the analytical philosophy of mind): the feeling body becomes manifest in holistic corporeal stirrings such as vigour and languidness, in one's being corporeally gripped by emotions and room-filling atmospheres, and equally in one's corporeal orientation in the world in contexts of perception, action and spatial navigation. Moreover, the feeling body presents an absolute location of subjective orientation and opens the dimension of a predimensional, surfaceless space. It is worth pointing 
to Schmitz' theory of space here in particular, because it is one of the most characteristic elements of his overall approach. Space, according to Schmitz, is not originally encountered as the measurable, locational space assumed in physics and geography, but rather as a predimensional surfaceless realm manifest to each of us in undistorted corporeal experience, for example in hearing voluminous sounds or sensing atmospheres. Examples of surfaceless space include the massive, roomfilling sound of a giant church bell, but also the shrill and sharp cry of a bird of prey. The weather, too, presents surfaceless spaces that are felt immediately in our bodily responsiveness to the atmosphere surrounding us. Crucially, the felt body itself is a surfaceless space, or more precisely an assemblage of many such spaces: corporeal "islands" such as the stomach region or the soles of feet are felt as diffuse but still separately identifiable spatial realms. Not surprisingly, Schmitz argues for the primacy of felt predimensional, surfaceless space, undertaking to demonstrate that the measurable, three-dimensional physical space is a derived, theoretically stabilised construction imposed upon original spatial experience on which it is conceptually dependent.

Returning to the felt body, another central concept is that of the 'vital drive' with its dual tendencies of 'expansion' and 'contraction'. According to Schmitz, the often nonspecific, diffusely localised corporeal feelings operate most of the time in the form of a pulsating rhythm in the felt body constantly oscillating between corporeal expansion and contraction, regularly at work already in breathing. This oscillation he christens 'vital drive'. Corporeal expansion is a marked widening of the felt space in the region of one's body, most notably occurring in states of relaxation. Characteristic examples of corporeal expansion are the experience of beholding of a wide, beautiful landscape, the first breaths outside in fresh air after having been locked inside a cramped and stuffy room, or the pleasant relaxing of the felt body when gently gliding into a hot bathtub. The opposite pole of corporeal contraction is a marked narrowing of he felt body, often in states of sudden, unexpected change to one's bodily orientation - such contraction occurs in states of shock, in panic or moments of great focus and concentration. Usually, expansion and contraction are dynamically related-Schmitz speaks of a 'dialogical character' of the vital drive. Take the example of shame. The corporeal dynamic in a state of shame is a process that starts from a corporeal openness towards the social surroundings populated by significant others (domination of expansion) into the contraction of oneself in a submissive movement to hide away from the merciless gaze of those nearby (domination of contraction). In anger, the opposite tendency is conspicuously at work: an expansive impulse originating in the contracted centre of the felt body, urging outward into the open as a strong movement impulse or action tendency directed at specific others as the ones to be punished or yelled at.

The felt body with its characteristic corporeal dynamics between expansion and contraction and its sensitivity to surfaceless spaces and room-filling atmospheres forms the backbone of Schmitz' theory of subjectivity and self-consciousness. The key notion here is that of affective involvement: the conscious subject's constantly being affected by and involved with what goes on-an involvement both realised and mediated by corporeal feelings that in turn make manifest (disclose) goings-on in the environment. Affective involvement is an immediate, pre-reflective, not yet articulated self-consciousness - Schmitz calls it "self-consciousness without identification". It can be characterised further by noting the irrevocable 'mine-ness' that is stamped upon 
every experience of a conscious subject. Conscious life in this basic, non-reflective form is what Schmitz calls "life in the primitive present" - a form of awareness that fuses together the five basic existential dimensions of here, now, being, this and $I$, so that an undifferentiated pure presence of 'mine-ness' is all that remains. While extremely rare in its purest form (encountered in states of shock or exuberant ecstasy), Schmitz assumes that the primitive present nevertheless grounds all forms of selfconsciousness. Without the originary mine-ness of the primitive present, our selfascriptions would lack a foundation in experience. All we could do in its absence, according to Schmitz, is offer ever more verbal self-descriptions without being able to grasp what it is that we thereby describe.

In the text presented here, Schmitz begins, after some brief historical stage setting, by outlining his view of self-consciousness, explaining affective involvement, the felt body and the vital drive along the way. He then develops a sketch of his theory of emotions as "atmospheres poured out spatially"-room-filling phenomena occupying surfaceless space around the conscious subject, dynamically engaging or "gripping" the felt body in characteristic ways specific to each distinguishable type of emotion. Mentalism is thus rigorously avoided, however at the expense of what at first sight is a highly counterintuitive claim: that emotions exist in public space, not in an individual's mind (and neither "in" the felt body, for that matter). Schmitz defends this thesis both conceptually and by describing noteworthy examples. His conceptual move consists in introducing the notion of a "half entity" to place alongside the concept of a thing ("full entity"). Half-entities are entities whose duration is interrupted and whose mode of influence is not conceptually separable from their interrupted persistence as an entity. The wind, the human voice, glances, musical melodies, meteorological atmospheres, and electrical and other forces such as gravity are cases in point. According to Schmitz, emotions are like that, existing out there in public space, but not such that they magically remain when no one to be moved by them is still present. Schmitz' vivid examples of emotions as existing in public space centre around the radiance of emotions into the surroundings, so that even those initially unaffected are drawn into what is then fittingly described as emotional atmospheres. In this way, especially grief, shame and anger seem to possess a room-filling authority that regularly affects or "grips" even total strangers despite their being unrelated to the events, situations and persons that gave rise to these emotions in the first place. In this, emotions as authoritative, room-filling atmospheres are radically different from other kinds of corporeally moving impulses or stirrings such as hunger and thirst or vigour and languidness, which are felt only by an individual person and by no one else.

We hope that this introduction has kindled some interest in contemporary readers that believe in the relevance of phenomenological inquiry to the interdisciplinary study of the human mind and personhood. Almost needless to say, Schmitz isn't playing very much by the rules of academic journal publications - his relatively short text covers far too much ground to ordinarily be acceptable for a scholarly article grappling with a neatly circumscribed research question or trying to prove or disprove a limited claim or hypothesis. Instead, a broad perspective is opened up and motivated and a wide-ranging system of conceptual and descriptive alternatives is sketched in the form of a coarse orientation. The following is thus a very first glance into a different world, a message in a bottle sent out to find readers in a different 
discursive universe. The time for this might be exactly right given the current movement towards embodied, embedded, extended and enactive approaches in philosophy of mind and cognitive science, the new vogue of phenomenological approaches in philosophy and psychiatry, the growing dissatisfaction with individualist and representationalist mentalism and amidst the recent rediscovery of the felt body as a crucial medium and vehicle of personal life.

\section{Emotions outside the box - the new phenomenology of feelings and corporeality (by Hermann Schmitz)}

In my opinion, emotions are atmospheres poured out spatially that move the felt (not the material) body. This change in the conception of emotion is contingent on an anthropological revolution by means of which I wish to replace the dominant trend in human self-interpretation that has loomed large in European intellectual culture since Democritus and Plato. If one goes along with this revolution, the new way of seeing emotions becomes natural. Otherwise, it remains disconcerting. The trend I am challenging holds that man consists of a material body and a soul. The term "soul" is insubstantial here; the criticism remains valid if it is replaced by terms such as "Geist", "mens", "mind" or the idea of consciousness as the locus of states of the soul. This has been commonplace since Descartes, Locke, Kant, James, Husserl, Sartre and all their followers. This way of seeing things is based on the paradigm of human understanding of the self and the world introduced in Greece in the second half of the 5th century B.C. I term it the psychologistic-reductionist-introjectionist objectification and characterise it as follows: The realm of experience is dissected by ascribing to each conscious subject a private inner sphere containing their entire experience. This is done, at first, under the name "soul". The external realm remaining between the souls is ground down to features of a few kinds that are ideally suited for statistics and experiments due to their intermomentary and intersubjective identifiability, measurability and selective variability. The remnants of this grinding down are either explicitly — as, for instance, in the case of the specific sensory qualities - located in the souls or are ignored. But even so, they wind up there furtively, so to speak. Among them are the emotions, furthermore the felt body [Leib] and corporeal [leiblich] communication (e.g. in exchanging glances), significant situations and with them impressions charged with significance, as well as surfaceless spaces and their occupation (e.g. by wind and weather). ${ }^{3}$ Thus, the greater part of spontaneous experience of the world is lost sight of to apprehensive attention.

The psychologistic-reductionist-introjectionist objectification with its consequent dogma that man consists of body and soul fails in that the relation of the conscious subject to their private inner sphere cannot be adequately characterised, even though a number of suggestions are in place. Some, for instance Hume and Mach, take the conscious subject to be a bundle of states of the soul, e.g. perceptions or sensations. Such a view can only seem plausible in the armchair; if matters get serious, if you, for instance, are on fire or are tormented by a burning sense of shame, you immediately notice that it is you who is suffering and not that a bundle of

\footnotetext{
$\overline{3}$ These notions will be explained later on.
} 
perceptions is merely going through certain changes. Plato identifies each and everyone with their soul (1960, 959 a.b). Aristotle holds that everyone actually is their superhuman nous, the better and the governing in them (2004, 1178 a 2-4). Kant (1971, 270) and Husserl (1913, 160 and 109) posit a subject that, according to Husserl, is pure ego and nothing more ["reines Ich und nichts weiter"] prior to anything observable in the soul or the body. The latest addition to this list can be seen in the slogan used by the avant-garde of materialist neuroscientists: "I am my brain". Each of these self-interpretations has shortcomings in itself, but they all share an intrinsic error: They come too late. They are offers to the conscious subject to take something as itself. A self-consciousness of this type I term self-ascription. On it are based the specifically personal abilities of giving an account of oneself, allotting oneself one's place, taking responsibility, etc. Therefore, I characterise the personality into which a normal, healthy human develops after infancy as a conscious subject with the ability of self-ascription. Self-ascription is an identification of something with oneself, performed by the conscious subject. It can easily be turned into a definite description of the conscious subject by giving specific information. This definite description of oneself differs from all other definite descriptions in its peculiar inadequacy. By means of any definite description you can be made familiar with the thing described, e.g. with a hotel room for the night by specification of city, street, street number, floor and room number. Only in the case of self-ascription must the reference of the identification (what something is identified with) already be known prior to the identification. Otherwise, e.g. in my case, the result would be a progression to ever new characterisations, e.g., from a man born in Leipzig in 1928 to a professor emeritus of philosophy, in each case with the addition of information sufficient for definite description. In no case would it turn out that it is precisely I who is this individual; for all appropriate specifications of, on the one hand, Hermann Schmitz and, on the other, Alexander the Great contain nothing that would indicate that I am, e.g. Hermann Schmitz and not Alexander. In order to know this I must already be acquainted with myself before any identification. Only then can I, based on the experiences I have and subsequent reflection on them, allot myself the appropriate place in the world, in the case at hand, that of Hermann Schmitz. If I am mistaken in so doing, e.g. because I am dreaming or suffering a delusion, that which I am identifying with myself is thoroughly out of order. But this changes nothing about what I identify it with, namely myself; for the acquaintance with myself I already bring to identification and retain it throughout all self-ascriptions.

So self-ascription is only possible if it is based on self-consciousness without identification. And such self-consciousness genuinely exists in the form of affective involvement. If I am, e.g. in pain, I immediately know it without having to find a sufferer to whom I ascribe identity with myself. Furthermore, there are states of upheaval or shock with increased or, on the contrary, reduced motion in which the conscious subject has no access to themself as the referent of an identification but nonetheless distinctly feels themself in the intensity of excitement or derangemente.g. raging anger, panicked fear, mass ecstasy, devoted struggle in the heat of the moment, being sunk in melancholy. Such self-consciousness without self-ascription is made possible by the subjective facts peculiar to affective involvement. In their plain factuality, they already contain reference to oneself, respectively to the experiencer. As a result, they can be predicated by, at most, one person under their 
own name. This stands in contrast to objective or neutral facts, which can be predicated by anyone, granted they know enough and are sufficiently articulate. The facts that are subjective for someone are richer in containing this subjectivity than the pale and neutral ones that result from the former by grinding down subjectivity. If, for instance, I sincerely say "I am sad", this contains more than saying that Hermann Schmitz, disregarding the fact that I am him, is sad, i.e. the actual affectivity and intensity of personal involvement. This surplus persists despite the complete equivalence of the propositional contents of both facts. In both cases, the same person is determined by means of the same fact including the affective involvement that is a necessary part of sadness. Nevertheless, the subjective fact is richer than the neutral one. This difference does not concern the propositional content, but the factuality, which is richer in the case of subjective facts than in the case of the pale objective ones. The difference lies not in a merely private inner mode of presentation as against an external one of objective facts. This is plain to view in that the personal pronoun "I" as well as its equivalents cannot simply be replaced by a proper name, as in the case of neutral facts, if we are reporting on facts of affective involvement. Examples are declarations of love, admissions of sin and calling for help. "John Smith loves you", "John Smith has sinned", "Help, John Smith is drowning": These expressions fall short of the adequacy of expressions appropriate in the situation: "I love you", "I have sinned", "Help, I am drowning".

Therefore, facts of affective involvement contain a self-consciousness prior to any identification and self-ascription, since in their plain factuality, without regard to their propositional content, the subjectivity for the conscious subject already contains a 'mine-ness' [Meinhaftigkeit], as Kurt Schneider has called it $(1950,130)$. This priority of self-consciousness is only possible if, in the case of affective involvement, the conscious subject is, without identification, aware of itself. Occasions of this awareness are marked by the sudden affectedness accompanying new experience, which disrupts duration [Dauer] and exposes the present, for instance, in fright, in a violent jerk, in a twitch of pain or if one, either literally or metaphorically, is dumbstruck or has the ground knocked from under one's feet. In cases like these, orientation, circumspection and knowledge are overridden by an experience of contraction [Engung] that leaves no leeway for evasion. Nonetheless, the mine-ness of one's being affectively involved remains and coincides with the contraction, which presents only this: itself in absolute identity without any further characterisation. In such cases, I speak of the primitive present, in which the five elements here, now, being, this and $I$ are fused. The coincidence of these elements makes superfluous a bridging by identification. The place of a relative identity of something with something is filled by an absolute identity of being it yourself. In this way, the conscious subject, without the need for identification, originally becomes acquainted with themself.

The primitive present is a rare, exceptional case. However, it influences all conscious experience, especially affective involvement by means of the vital drive, which is formed by the intertwinement of tendencies towards contraction and expansion [Weitung] running counter to one another. A basic example is the felt intake of breath. It begins with a predominance of expansion in the region of the chest or the abdomen; this predominance gradually phases over into a predominance of contraction, which is released by breathing out before it becomes unbearable. In fear and pain contraction is predominant leading to the 
inhibition of expansive impulses; in lust and surges of anger an expansive impulse prevails over the resistance of contraction. If contraction is suspended, as in severe fright, the drive is frozen or paralysed; if expansion phases out, as in dozing, falling asleep or after ejaculation, it is lax; thus it consists solely in the intertwinement of contraction and expansion. In the vital drive's contracting element, the primitive present is sketched as accessible, for only in it does the gliding of transitions come to a halt in such a way that something can define itself as this in absolute identity. For this, accessibility by means of contraction is sufficient; it is not necessary to fully submerge oneself in the primitive present. The accessibility of the latter is sufficient, in all affective involvement, for selfconsciousness without self-ascription, even in the case of expansion in joy or relief. With its ties to corporeal contraction, be it only in a sense of getting away from it, even the affective involvement itself dissolves and phases over into dull indifference. In consequence, the contracting kinds of affective involvement are better suited for self-consciousness without identification than the mainly expansive ones, e.g. joyous exuberance, in which one feels larger than life.

The original locus of identity and difference is the primitive present. Identity, at first, is absolute identity of something as itself and as different from anything else. This experience does not yet contain the idea of relative identity, i.e. of something being identical with something else. Difference belongs to the primitive present, because the sudden dawning of the new, the peak of contraction interrupts duration that then fades into no longer being. As such, the difference from the interrupted duration sinking into no-longer-being belongs to the primitive present with exposed identity. This original experience of identity and difference is taken on by the vital drive which, in the form of contraction, connects to the primitive present. It is put to use in all behavioural routines. Thus, such routines are protected against confusions. This is how convenient - often spontaneous-complex movements of the body succeed. This not only holds true of smooth operations, but also of more or less dramatic conflicts in corporeal communication. The dialogue of contraction and expansion is straddled until it becomes a conflict between partners. A simple example is pain, e.g. in one's teeth or stomach. Fear and pain are similar in that they are both marked by a suppressed drive to escape. The drive is expansion that is suppressed by contraction. An important difference, however, consists in the fact that the person feeling fear can, despite the contraction, follow their drive: they can flee in panicked fear. By contrast, someone in pain can only flee symbolically by crying in pain and rearing up. They are confronted with the pain and have to grapple with it. Their own condition is at the same time confrontation with an opponent. The sense of overpowering gravity felt in slipping and only catching one's balance at the last moment is merely an opponent, just like the sense of a strong headwind. Both opponents, however, are only felt in the form of expansion and contraction of one's own body. This straddling reaches its fullest extent in encountering other creatures, e.g. in exchanging glances which creates a joint vital drive composed of expansion and contraction or in evasion of harmless or dangerous encounters guided by vision. An example: if a powerful mass (a stone, a fist) impedingly approaches, one will jump or turn aside so that collision is avoided. In so doing, one does not see one's own body and one can also not determine which relation and distance it has to the impeding object. Rather, vision connects to it and spontaneously grasps the 
impeding suggestion of motion. Thus, via the bridging function of vision, is generated a shared vital drive that guides motor activity and enables graceful evasion. This is corporeal communication.

It creates a shared vital drive composed of contraction and expansion. Consider also the avoidance of harmless or dangerous encounters by directing your vision. Corporeal communication through the channel of the vital drive-in such cases, I speak of encorporation [Einleibung] - exists in an antagonistic mode with attention to others as well as in a solidary mode without such attention (e.g. tempestous courage or the panicked flight of a troop, when singing, playing music, rowing, sawing together, by rhythmical calls, clapping, drumming). It is the basic form of human contact, even of perception itself by means of adaptation and reaction. As mutual encorporation with its fluctuation of the dominant pole of contraction, it is the foundation of the certainty of dealing with another conscious subject. Encorporation is the unfathomably rich source of situations in which what is diverse is holistically synthesised, i.e. in a manner externally detached and in itself coherent. This is achieved by means of an internally diffuse meaningfulness (i.e. one that is not, or not entirely, segmented into singular elements; thus not increasing a number by 1) of states of affairs, programmes and/or problems. Particularly apt examples are situations of acute danger that call for immediate resolution. Someone driving a car in the rain on a motorway with dense traffic, who only avoids an impeding accident by sudden evasion, breaking or acceleration, has to at once grasp relevant states of affairs, the problems of collision and of possible collisions in the case of evasion. This is achieved in an internally diffuse meaningfulness, since there is no time for analysis and an immediate appropriate reaction is called for. It is realised by an antagonistic encorporation into the situation on the motorway in front and (via the rearview mirrors) beside and behind them, as well as into the vehicle with hands, feet and the entire felt body which is receptive to the vibrations that communicate the roadholding and the structure of the road.

In animal (partly also human) communication by means of calls and cries (e.g. cries of alarm, mating calls, cries of grief), such situations are evoked, modified and answered as wholes. However, they are not analysed. Thus, from gliding duration, the primitive present, corporeal dynamism and corporeal communication an immensely variegated and finely differentiated field of events and experience arises, which I term life in the primitive present. Animals and infants are restricted to it.

What is still missing, however, is singularity. Something is singular if it increases a number by 1 . This is logically equivalent to the following condition: Whatever is an element of a finite set. Numbers are properties of sets. Sets are sets of instances of kinds or determinations, e.g. the set of humans, the set of numbers, the set of accidents. Something can be singular only as an instance of a kind. Here the term "kind" covers everything of which something can be an instance. Singularity arises from the complementation of absolute identity (available already in the life in the primitive present) by determination as an instance of a kind. Since there are always many different kinds which come into consideration, absolute identity is further elaborated into relative identity of something with something; i.e. of something under a certain determination with the same thing under another determination (in the borderline case of tautology, once again under the same determination). The determinations or kinds are gained by the fact that sentential expressions isolate and 
(re-)combine singular states of affairs, singular programmes and singular problems from the internally diffuse meaningfulness of situations. This is the basic form of human self-assertion and of getting a grip on the world. This makes humans superior to animals: They take control of situations by meticulously reconstructing them as constellations or networks of singular factors and re-arranging these networks so as to probe possibilities in anticipation.

With their provision of singularity sentential expressions mark the first step beyond life in the primitive present towards the world as the field of, or frame for possible singularisation. Understood this way, the world receives its structure by means of unfolding the five elements fused in the primitive present: here, now, being, this, I. The here of the primitive present, the absolute location, unfolds into a system of relative locations that are determined by positions and distances in the manner of a co-ordinate system. Only thus is meaning bestowed on expressions indicating that something is somewhere and will remain there or is moving somewhere else. The now of the primitive present, the absolute moment of sudden emotional involvement, unfolds into a succession of relative moments in modal temporality which connects the division into past, present and future (as well as the associated notions that time is a stream, that the past is growing, that the future is shrinking and that the present is moving) to the ordering of events by means of the relations between earlier, later and simultaneous. The this of the primitive present, the absolute identity, unfolds into manifold relative identities with something(s). The being of the primitive present unfolds by means of the contrast to not-being in its full range instead of the no-longer-being of duration disrupted by the dawning of the new. Here singularity transcends the boundary between being and not-being in a way that makes possible memory, expectation, fear, hope, planning, fantasy and playful as-if-identification. The element $I$ of the primitive present initially unfolds when the absolutely identical conscious subject of the life in the primitive present becomes a singular subject by means of self-ascription as an instance of a kind. For it, states of affairs, programmes and problems are isolated from the internally diffuse meaningfulness of situations, all of which are initially subjective for the conscious subject in the way explained for the case of facts above. This subjectivity is lost for a part of these meanings. Thus it happens that through them the conscious subject becomes alienated from a lot of things when they are seen in the light of purely objective or neutral facts. This is similarly so for non-actual states of affairs, programmes or problems. Vis-à-vis the alien, a private sphere can emerge, which I have elsewhere intensively examined as personal situation [persönliche Situation and persönliche Eigenwelt] with a view to the development of, and the relation to the personal subject (cf. Schmitz 1999, 106-36).

Only now has the time come to settle an old score with the psychologisticreductionist-introjectionist objectification. The philosophical tradition since Democritus and Plato, as well as the folk theory of human self-understanding following in their footsteps, has, under the name "soul" (or "mind" or other terms), assigned to the conscious subject a private inner sphere. As touched upon previously, however, it has dedicated only a few and, what is more, dubious thoughts to the question of the relation in which the conscious subject stands to this sphere. All these proposals come too late, since they are only offers of seemingly objective facts to selfascription. The latter, however, is only possible by means of an original 
acquaintanceship with oneself in a non-identifying self-consciousness. From the beginning, this lead should have been followed in order to find the subject that is acquainted with itself. In that case, one would have become aware of the subjective facts of affective involvement that is always corporeal [leiblich]. One would, furthermore, have become aware of the felt body as the carrier of corporeal impulses, i.e. those that someone feels as belonging to themself in the vicinity - not always within the boundaries - of their material body without drawing on the five senses and the perceptual body schema parasitic on them. Such impulses are, e.g., fright, fear, pain, hunger, thirst, lust, vigour, disgust, tiredness and generally all affective involvement with emotions. I have thoroughly examined the felt body with its peculiar spatiality and dynamism many a time; as well as the primitive present and the vital drive (cf. Schmitz 1964-1980, esp. volumes II and III). ${ }^{4}$ Their indispensability for personhood and self-consciousness on which I have elaborated here is central to this dynamism. The tradition has completely ignored the felt body and confused it with the material body, although they belong to different forms of space. Whereas the material body belongs to a space containing surfaces, the felt body belongs to a surfaceless one, just like sound, the weather or silence. In no corporeal impulse can surfaces be observed. For self-ascription, a person is dependent on a constant balancing act between personal emancipation and personal regression; personal emancipation is neutralisation of meaning by means of which what is private sets itself off from what is alien. On the other hand, personal regression is resubjectification of what has been neutralised by submergence in the corporeal life in the primitive present. For the left projection (first entry of an ordered pair [Referens]) of self-ascription, i.e. that which it ascribes to itself, a person needs personal emancipation. For the right projection (second entry of an ordered pair [Relat]) of self-reference in the primitive present, however, it needs personal regression in which it finds itself affectively involved prior to any self-ascription. This unstable discrepancy bars the containment of all experience in a private inner sphere. The personal situation that replaces it is inherent in the person. However, the person, again and again, plunges into the pre-personal life in the primitive present by means of corporeal communication. Furthermore, its personal situation is not merely a shell, but also a partner that the person has to consult like an oracle in order to will something. Consciousness, too, with its many allegedly introspectible contents is a misapprehension. One has ascribed to it a numerical diversity of many individual components. Much rather, it is a being-conscious with a type of diversity that unites singularity and multiplicity. This can be observed in the case of relational consciousness. The idea of a difference between sun and moon contains three component ideas, the collation of which would, however, yield nothing similar to the former, since the difference has no features of the sun, the sun no features of the moon, etc. Addressing this issue here would, however, take us beyond the scope of our present enterprise (cf. Schmitz 2004).

Finally, by means of this circuitous preparation, the way has been cleared for an unbiased assessment of the emotions. They have been freed from the spell of a private inner sphere of the soul, because this inner sphere itself has been shattered by

\footnotetext{
$\overline{{ }^{4} \text { See also Schmitz } 1989 \text { and } 1990 .}$
} 
its inability to be the soul of a possessor or subject. The foundation of personhood is not the soul, but the life of the felt body as a life in the primitive present, marked by corporeal dynamism and corporeal communication, without a closed-off private inner sphere. Whatever goes beyond this as specifically personal, i.e. the personal situation and the personal sphere, is highly significant for the experience of the person, without, however, containing it in its entirety.

I want to illustrate the significance of this openness to emotions by using the example of anger. Traditionally it has been seen as an introspectively accessible state of the soul, a "passio animae", as Thomas Aquinas has called it, following Aristotle. In reality, however, it is experienced without any reference to a soul. Much more it is experienced as a force impacting the lived body in a manner comparable to a stroke of lightning or the overpowering sense of gravity you feel when you slip and only catch your balance at the last moment. However, the trajectory here, rather than downward, is forward and marked by an even more important difference: You resist the overpowering sense of gravity, but you go along with the moving force of anger to some extent, at least initially. All affective involvement is Janus-faced in that it is, on the one hand, a passive experience and, on the other, an activity of engaging this experience with an attitude, as I have argued in my theory of freedom (Schmitz 2007). This attitude can be a defensive stance, as in the case of fear. In the case of being moved by anger it is, at first, offence in agreement with the impulse of the moving force. Up to this point, the involvement is pre-personal, belonging to a life in the primitive present; a personal response by surrendering yourself to and/or resisting can only take place ex post, when the simultaneously pre-personal and personal conscious subject is already in the grip of anger. This is the distinguishing feature that sets being moved by emotions off from mere affective involvement by means of corporeal stirrings such as hunger, thirst, tiredness and pain, which are not emotions. Such corporeal stirrings the person can almost always observe and take a distance to them. Whereas in the case of an emotion, before the person can intentionally take a stance towards it, they always find themself already situated in a stance one way or another and can no longer confront it in an unbiased way. They might even become inconsistent with themself, i.e. the spontaneous initial stance. In consequence, being moved by emotions is much harder to observe or register than affective involvement by mere corporeal stirrings. However, being affectively involved with emotions, i.e. being moved itself is a corporeal stirring. This corporeality is borne out by a surprising reliability of the gestures shown by persons moved: A person in distress will spontaneously sigh and assume a hunched and limp posture; a person feeling shame will automatically cast their eyes downward; an angry person will clench their fist and speak in an irritable, even a sharp voice; a happy person naturally shows complex expressive behaviour - a light and springy step, laughing eyes, an inclination to smile, breathing freely, articulating jauntily-even though an experienced actor would be needed to convincingly re-enact such behaviour. Only if the involvement is not entirely authentic, i.e. if acquiring the respective state has not entirely gone into passively experiencing the impulse of the moving force, do you feel awkward, as, for instance, is so often the case with pity. How can the feeling be expressed adequately? What way of offering condolences is appropriate? Only if pity sweeps you away as though it were your own suffering, does showing it become natural. 
Emotions are atmospheres poured out spatially. An atmosphere in the sense intended here is the complete occupation of a surfaceless space in the region of experienced presence. This surfaceless space, apart from emotions, can also be occupied by the weather experienced as enveloping you or by (e.g. festive, pregnant or calm) silence. There are also atmospheres that do not so completely occupy the space of experienced presence: the holistic corporeal stirrings that strike you at once without being segmented into individual islands of corporeality, for instance, in the morning after waking up, when you feel languid and weak and are urged, with the help of a few cups of coffee, to boost this holistic condition. Such merely corporeal atmospheres are locationally circumscribed. This stands in contrast to the way in which emotions are (or have a claim to being) unboundedly poured out, as I will shortly clarify. Objections to the spatiality of emotions of the sort that they are not three-dimensional bodies, surfaces or lines, that they are not round or square, that they could not possibly be located at this position or that distance, are based on the false presumption of an space containing surfaces. However, the space of emotions is as surfaceless as that of sound or silence, of the weather or a driving headwind (including movement without change of location), of the water plunged into and crossed by a swimmer, as that of freely unfolding gesture, of feeling something in your own body.

Tempted by the model of Greek geometry proceeding with compass and ruler and its continuation in Cartesian co-ordinate systems, one is all too ready to take space as a system of relative locations that mutually determine one another by positions and distances. Positions and distances are read off invertible connections that need to be charted in surfaces in order to provide a network of spatial orientation that remains stable independent of the perspective one takes on them. However, such a locational space logically presupposes surfaceless spaces. For in it, movement can only be construed as a change of location and motionlessness only as remaining in a location. On the other hand, location conceptually presupposes motionlessness. After all, it can only be determined by its position and its distance to motionless objects; if these were to move, its position and distances to them would be shifted and the location would have become another. Thus the objects located there would have changed their location, i.e. they would have moved although they remained in the same location. In that case, motionlessness would be movement, and that is impossible. Therefore, location presupposes motionlessness and, conversely, motionlessness, understood in terms of locational space, presupposes location. A consequence of this is that, on the assumption that space is merely locational space, it is impossible to say non-circularly what location and motionlessness are. This holds for absolute space as well as for space contingent on the choice of a coordinate system. The lesson to be learned from this conceptual circularity is that one already has to be familiar with motionlessness if one wants to introduce a notion of locational space. This familiarity can only come from surfaceless spaces. Therefore it is futile, from the high-horsed belief in a monopoly of mathematical and physical space, to look down upon surfaceless spaces as poetic illusions or metaphors for a vague sense of feeling with, at best, psychological value. For such a monopoly is not tenable for purely conceptual reasons.

Another objection against the spatiality of emotions is based on the expectation that anybody who is in such a space in which an emotion is poured out would have 
to be able to feel it just like they feel the weather; as a matter of fact, however, various people are haunted by very different emotions that are often inaccessible to others. All this is independent of being located at this or that position. This objection results from an erroneous objectification of emotions which I, too, have abetted by, in all too passionately opposing locating emotions in souls, asserting that emotions are no less objective than roads, only less easy to get a fix on. Roads are full entities in the sense of material things and share two properties with all full entities: First, their duration is only possible continuously and without interruption; second, as causes, distinct from their mode of influence, they cause an effect. For instance, a stone (cause) by means of a thrust (mode of influence) can cause movement of or damage to the object hit (effect) or a pharmaceutical (cause) by means of injection (mode of influence) can cause anaesthesia or diarrhoea (effect). In contrast, emotions are half-entities like the wind, voices, the sense of overpowering gravity, electric shocks, pain, melodies and many sounds such as a shrill whistle or an earpiercing noise, night, time, especially if it seems to become unbearably long in boredom or tense anticipation. The duration of half-entities can be interrupted; the characteristic voice of someone resounds, falls silent and resounds again. There is no point asking how they passed the time in between. In the causality of half-entities cause and mode of influence are one thing; although, in the case of the resounding voice, physics constructs a host of intermediates such as sonic waves or electrical communication in the nervous system, but these are, at best, useful posits in the service of schematic prognosis; but there is no space here to epistemologically assess natural science. Both scientific and pre-scientific physics have an interest in doing away with half-entities, as prognosis requires an ordered world in which causes can be assessed with a view to their effect before they exert an influence. For this reason the experienced wind is re-interpreted as moving air - a hypothesised full entity - an electric shock as electricity, more recently, even overpowering gravity as gravitons, elementary particles mediating the force of gravity. From a phenomenological point of view, a voice immediately affects without a distinction between cause and mode of influence. Half-entities are different from raw sensory data in that their character remains the same despite changes in its modes of presentation. A sequence of sounds increases, a voice does not.

Emotions are half-entities. They immediately corporeally and affectively involve the conscious subject as modes of influence indistinguishable from causes. They persist with interruptions like pain as an intrusive opponent with which one has to deal. Sometimes they seem to appear from nowhere and take the moved person aback ${ }^{5}$; very often they are called up time and again, with interruptions, by events in the narrative of a person's life. An example would be an emotion of bitterness following being slighted or being denied something, or simply resulting from the person's present circumstances of living. As such, they are only accessible to the person through their individual perspective shaped by personal experience. Therefore, it is not surprising that one's neighbour often does not notice the atmosphere that takes hold of one in the form of an emotion. This impermeability is

\footnotetext{
$\overline{5}$ cf. Eduard Mörike's poem Verborgenheit.
} 
also due to differences in the ability to be moved. These are partly corporeally conditioned. An emotion moves corporeally by stirring the vital drive composed of expansion and contraction. How easily this happens is dependent on the vital drive's form of binding. A drive capable of oscillating and in which phases of a predominant contraction or expansion tend to rhythmically alternate as well as a drive capable of being segmented, and from which components of contraction or expansion can be isolated, are better suited to being moved than compact drives in which expansion and contraction hardly come apart. For another thing, conditioning by one's personal history affects how open or concealing a person is in dealing with the impulses of the moving emotion. On the other hand, however, it is incorrect to say that emotions are always private affairs, i.e. that they are only accessible to one individual. Just as well, and maybe not less often, there are collectively moving emotions, e.g. the boundless courage or panic of groups as momentary incidents or love as the atmosphere of a situation with shared responsibility of a couple or a larger group of people. The latter is an emotion that is sustained and managed by loving in the form of intransferable facts that are subjective for each individual (Schmitz 1993).

In conclusion, I want to adduce a few examples of my view that emotions are corporeally moving atmospheres poured out spatially. For this purpose, I examine processes in which an atmosphere poured out over the sphere of the present is, at first, merely perceived and, then, corporeally moves the perceiving person or affects them otherwise. As Goethe's Faust, in a lustful and infatuated mood, secretly enters Gretchen's chamber, he cries out:

Breath and the feel of stilness around me,

Of order and contentedness, (Goethe 2005, verses 2691-2)

His initial way of feeling is quite contrary, but one can easily imagine how he is, perhaps just in passing, affected by the atmosphere. Compare a case in which the mood of a scoundrel or a wretch can, to their own surprise, be changed to be more peaceful or even pietous by the atmosphere of a church. Contemplative sincerity is an emotion that can affect a person as the atmosphere of an environment, e.g. the tranquillity of a spacious landscape. The atmosphere can creep up on them, so to speak. Such sincerity is a powerful emotion, but it involves no pleasure or pain. This stands against the millennia-old (cf. Aristotle 2004, 1105 b 21-23) common association of emotions with hedonic valence (up to the identification of both in Kant and subsequent psychology). An opposed atmosphere is that of ludicrous joy, which, poured out over a festive crowd, might be taken to be intrusive by a sincere observer and displease or disconcert them, but might also directly affect them. In such cases either people genuinely moved by the emotion can be made out or the atmosphere is tied to an appropriate environment that evokes it. But it also happens that an emotion which no one feels is in the air without being thus tied to anything. Confronted with an emotion of another type it can indirectly become intrusive. An emotion of guilt after a heinous deed often contains an element of fear as a precursor emotion to anger. In such fear the anger is felt as a threat although no angry person is to be found. In Faust, the evil spirit, like a quasi-inner voice, calls out to the guilty Gretchen: "Grimm fasst Dich (lit. trans.: Rage grips you!)" (verse 3806). It would be pointless to ask who is enraged here. The context is the killing of a relative. Similarly, Aeschylus' character Orestes, before encountering the Erinyes, 
experiences being overwhelmed by his guilt as fear that is a precursor emotion of an anger without there being an angry person:

Now listen. At this moment I am like a man

Driving a team of horses and not knowing where

The gallop's going to end. My wits chafe at the rein

Under my weakened grip, and warry me off the course;

Terror begins to sing at my heart and set it dancing

In anger (Aeschylus 1956, verses 1021-1025).

As a person feeling shame withdraws from their environment, shame is a particularly intimate emotion. But it can also happen that a person does not genuinely feel shame and, as such, is not really emotionally contagious, while their shame behaviour is embarrassing for bystanders or relatives, even if they are not present. In such cases, one can see that this intimate emotion, even without being genuinely moved by it, is a radiant atmosphere, for the same embarrassment also occurs as acute catastrophical shame. In such cases, one would say: "I am really embarrassed that ..." But it also exists as a fading emotion in which people feel embarrassed but do not cast their eyes downward, as does the person feeling fullblown shame. They might merely squint. I have elsewhere analysed the complex atmosphere of shame (Schmitz 2001, 2006). The atmosphere of joy is less complex. It is marked by a levitating inclination against the backdrop of which one is no longer impressed by the unchanged force of gravity ("to jump for joy", "to float on air"). This may also be due to a heightened feeling of strength induced by joy. But there is also a more passive kind of joy in which one can let oneself go, for instance, in the case of being relieved of serious worries. Nonetheless, in such cases, too, joy is uplifting and this can only be due to the directed atmosphere of the moving emotion.

The radiance of the atmosphere is particularly impressive in the case of grief. I illustrate it by showing up the social contrast between emotions. For this purpose, I compare joy and grief with two corporeal stirrings related to them, vigour and languidness. A sensitive person feeling joy will curb their expression of joy, e.g. fall silent, if they unexpectedly encounter a group of grief-stricken people. If, however, as a vigourous person, they encounter languid people, they will not be so reserved. Rather, if they want something from them, they will try to jolt them from their state, by use of words or physically. They might give them something to strengthen them or send them to see a doctor, etc. This difference has nothing to do with respect for human dignity, for the latter would demand rather that they be jolted so as to give them back a posture of pride and dignity. Much rather, the atmosphere of grief, as a force corporeally moving the joyous person, does not affect them in a way so as to make them feel grief themselves. Rather it is felt as an authority filling the space of the present that demands that the less weighty emotion of joy be curbed. Mere corporeal stirrings such as vigour or languidness are neither such room-filling atmospheres nor do they have an authority that compels those affectively involved.

Acknowledgments Hermann Schmitz thanks Jan Slaby for initiating and organising the translation of this text; Rudolf Owen Müllan for his careful and nuanced translation and Matthew Ratcliffe for his constructive comments on an earlier version of the manuscript. Jan Slaby and Rudolf Owen Müllan thank 
Hermann Schmitz for his patience and cooperation, the GNP and especially Hans Werhahn for providing funding for Rudolf Owen Müllan; Matthew Ratcliffe for his extremely helpful comments to an earlier draft and Steffen Kluck for his valuable assistance along the way.

Open Access This article is distributed under the terms of the Creative Commons Attribution Noncommercial License which permits any noncommercial use, distribution, and reproduction in any medium, provided the original author(s) and source are credited.

\section{References}

Aeschylus. (1956). The Orestian Trilogy. Translated by P. Vellacott. London: Penguin.

Aristotle. (2004). The Ethics of Aristotle: the Nicomachean Ethics. Translated by J. A. K. Thomson. Revised with notes and appendices by Hugh Tredennick; introduction and further reading by Jonathan Barnes. London: Penguin.

Fuchs, T. (2008). Das Gehirn-ein Beziehungsorgan. Stuttgart: Kohlhammer.

Goethe, J. W. V. (2005). Faust. Trans. by D. Constantine. London: Penguin.

Husserl, E. (1913). Ideen zu einer reinen Phänomenologie und phänomenologischen Philosophie, 1. Buch. Halle a. d. Saale: Max Niemeyer.

Kant, I. (1971). Preisschrift über die Fortschritte der Metaphysik. Akademieausgabe Band 20. Berlin: De Gruyter.

Moldzio, A. (2004). Schizophrenie. Eine philosophische Erkrankung? Würzburg: Königshausen und Neumann.

Plato, X. (1960). The Laws. Translated by A.E. Taylor. Dutton: Dent.

Schmitz, H. (1964-1980). System der Philosophie. 5 Volumes in 10 Books. Reprinted in 2005. Bonn: Bouvier.

Schmitz, H. (1989). Leib und Gefühl. Materialien zu einer philosophischen Therapeutik. Paderborn: Junfermann.

Schmitz, H. (1993). Die Liebe. Bonn: Bouvier.

Schmitz, H. (1999). Der Spielraum der Gegenwart. Bonn: Bouvier.

Schmitz, H. (2001). Braucht die Scham einen Zeugen? Ethik und Sozialwissenschaften, 12, 319-321.

Schmitz, H. (2004). Was bleibt vom Bewusstsein? Interdisziplinäre Phänomenologie Band 1 (pp. 295303). Kyoto: University of Kyoto.

Schmitz, H. (2006). Kann man Scham auf Dauer stellen? Berliner Debatte Initial, 17, 100-105.

Schmitz, H. (2007). Freiheit. Freiburg i.Br. München: Alber.

Schmitz, H. (2010). Jenseits des Naturalismus. Freiburg i.Br. München: Alber.

Schneider, K. (1950). Klinische Psychopathologie (3rd ed.). Stuttgart: Thieme. 